\title{
MIXED CONNECTIVE TISSUE DISORDER WITH PREGNANCY
}

Narmadha Narendhran ${ }^{1}$, Jamila Hameed ${ }^{2}$, Abhinaya ${ }^{3}$, Vivek Salguna ${ }^{4}$

\section{HOW TO CITE THIS ARTICLE:}

Narmadha Narendhran, Jamila Hameed, Abhinaya, Vivek Salguna. "Mixed Connective Tissue Disorder with Pregnancy". Journal of Evolution of Medical and Dental Sciences 2014; Vol. 3, Issue 18, May 05;

Page: 4847-4849, DOI: $10.14260 /$ jemds/2014/2522

ABSTRACT: Mixed connective tissue disease (MCTD) is a term involving the features of lupus systemic sclerosis, polymyositis, rheumatoid arthritis and high titre of anti ribonucleoprotein (RNP) antibodies, exact etiology is not known. It is characterized by microvascular damage, immune system activation leading to inflammation and excessive deposition of collagen in the skin, lungs, heart, gastrointestinal tract and kidneys. The females are being more affected especially after childbirth attributed to the hypothesis of microchimerism, the pathogenesis being a two way migration of fetal cells through the placenta. It cannot be cured completely but treatment with corticosteroids is helpful. ACE inhibitors are useful in renal involvement and hypertension. We had a case of mixed connective tissue disorder in a patient aged 28 years with 12 weeks of gestation for medical termination of pregnancy (MTP) and permanent sterilization. The complications are preeclampsia, preterm labor, fetal growth restriction, eclampsia, thrombocytopenia and infections like pneumonia, sepsis like syndrome and the maternal mortality rate is 325/100000. This is a unique case of MCTD wherein we had limited cutaneous disease like CREST-calcinosis, Raynaud's phenomenon, esophageal involvement, sclerodactyly and telangiectasia of a lesser degree. So early diagnosis and timely intervention is advocated to prevent complications.

KEYWORDS: Mixed connective tissue disorder, Pregnancy, Termination of pregnancy.

CASE REPORT: A patient aged 28 years gravida 4 para 2 live 2 abortion 1, and last child birth was two and half years ago with 12 weeks of gestation referred from dermatology department for MTP with sterilization. Patient had typical skin involvement like cutaneous systemic sclerosis, diffuse cutaneous skin thickening, rash which was photosensitive, difficulty in swallowing, Raynaud's phenomenon (cold induced digital ischemia), epigastric burning sensation, dysphagia. No renal involvement. Patient was anemic. Blood pressure was normal. Investigations showed platelet counts, clotting time, bleeding time, liver function test, thyroid function test, renal function test, total count and differential count as normal.

X-ray chest and ECHO showed left ventricular hypertrophy. Patient had investigations pertaining to MCTD done prior to admission in the dermatology department like Antinuclear Antibody (ANA), Anti- RNP, Anti Sm and skin biopsy which confirmed the diagnosis of MCTD and was on corticosteroids and hydroxyl chloroquine for the past 2 years. In view of the MCTD with pregnancy to prevent exacerbation of the disease during pregnancy hence the patient was taken up for MTP and sterilization. The post-operative period was uneventful and referred back to dermatology department to continue the treatment.

DISCUSSION: MCTD is an autoimmune disease with autoantibodies affecting multi organs like skin, joints, kidneys, lungs, liver and nervous system. It is more common in women, it may be diagnosed for the first time during pregnancy and the incidence is $10-30 \%$ of cases. In our patient the disease was first diagnosed when she was pregnant last time 2 years ago when she had spontaneous abortion 
and she had fatigue, weight loss, arthralgia, arthritis and the typical skin changes. She had ANA screening test, Anti-RNP and autoantibodies to double stranded DNA (dsDNA).

She had a skin biopsy done which proved MCTD. So for the past 2 years she is on hydroxychloroquine and prednisolone $1-2 \mathrm{mg} / \mathrm{kg} / \mathrm{day}$ and tapered the dosage gradually. During pregnancy MCTD flares up the disease and may progress to abortion, preeclampsia, HELLP syndrome $^{1}$, eclampsia, premature delivery ${ }^{2}$ anemia, intrauterine growth retardation (IUGR) ${ }^{3}$ and maternal mortality is increased due to renal failure, hypertension and cardiopulmonary complication.

Fetal mortality is $20 \%$. The vasculopathy nature leads to reduced placental blood flow; hence perinatal mortality is increased. .45

Some patients might have difficulty in opening the mouth during intubation so epidural anesthesia is preferred over general anesthesia and also aspiration due to esophageal dysfunction such patients is an added complication and worse complications are hypertension, renal failure, cardiopulmonary complications like pneumothorax, pulmonary fibrosis ${ }^{6}$. In addition to this there are cases reported of babies with chrondrodysplasia punctata born to MTCD mothers with high titre antiRNP.7

Previously the patient had spontaneous abortion two years ago just before this present pregnancy and she was diagnosed to have MCTD 2 years ago and was under treatment. MCTD causes abortion due to the vasculopathy nature of the disease. ${ }^{8}$ Thefetal wastage is increased in MCTD. Just like neonatal lupus syndrome due to crossing of maternal antibodies the fetus can have fetal hemolytic anemia, thrombocytopenia, leukopenia and congenital heart block. So also in systemic lupus erythematosus (SLE). ${ }^{9,} 10$

The incidence of MCTD with pregnancy is 1 in 22000 pregnancies, ${ }^{11}$ oral contraceptives may flare up the symptoms, intrauterine contraceptive devices (IUCD) may cause infection and the barrier methods which are advised may not be followed. Hence in view of the life threatening complications in the mother as well as the fetus, termination with permanent sterilization is the best choice.

\section{REFERENCES:}

1. Behluli I, Riehl J, Rath W. Mixed connective tissue disease and HELLP syndrome in pregnancy. Dtsch Med Wochenschr. 2007 Apr 20; 132 (16):878-80.

2. Chung L, Flyckt RL, Colón I, Shah AA, Druzin M, Chakravarty EF. Outcome of pregnancies complicated by systemic sclerosis and mixed connective tissue disease. Lupus 2006; 15(9): 595-9.

3. Maymon R, Fejgin M. Scleroderma in pregnancy. Obstet Gynecol Surv. 1989 Jul; 44 (7):530-4.

4. Doss BJ, Jacques SM, Mayes MD, Qureshi F. Maternal scleroderma: placental findings and perinatal outcome. Hum Pathol. 1998 Dec; 29(12):1524-30.

5. Papakonstantinou K, Hasiakos D, Kondi-Paphiti A. Clinicopathology of maternal scleroderma. Int J Gynaecol Obstet. 2007 Dec; 99 (3):248-9. Epub 2007 Sep 24.

6. Hoshino T, Kita M, Takahashi T, Nishimura T, Yamakawa M. Management of two pregnancies in a woman with mixed connective tissue disease, pulmonary fibrosis, frequent pneumothorax and oxygen inhalation therapy along with a published work review. J Obstet Gynaecol Res. 2008 Aug; 34:613-8.

7. Schulz SW, Bober M, Johnson C, Braverman N, Jimenez SA. Maternal mixed connective tissue disease and offspring with chondrodysplasia punctata. Semin Arthritis Rheum. 2010 Apr;39 (5):410-6. doi: 10.1016/j.semarthrit.2008.10.003. E pub 2008 Dec 24. 
8. Bodolay E, Bacskó G, Bezsilla E, Szegedi G. Pregnancy in mixed connective tissue disease. Orv Hetil. 1991 Mar 24; 132 (12):619-22.

9. Kaufman RL, Kitridou RC. Pregnancy in mixed connective tissue disease: comparison with systemic lupus erythematosus. J Rheumatol. 1982 Jul-Aug; 9(4):549-55.

10. Yildirim A, Tunaoolu FS, Karaaoac AT. Neonatal Indian Pediatr. 2013 May 8; 50 (5):483-8.

11. Chakravarty EF, Khanna D, Chung L. Pregnancy outcomes in systemic sclerosis, primary pulmonary hypertension, and sickle cell disease. Obstet Gynecol. 2008 Apr; 111 (4):927-34.

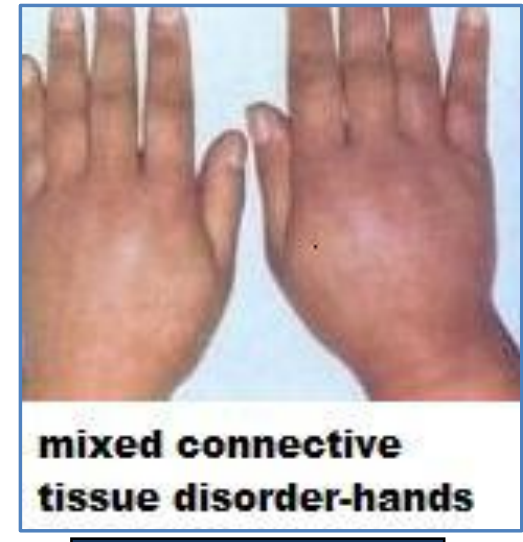

mtcd hand final

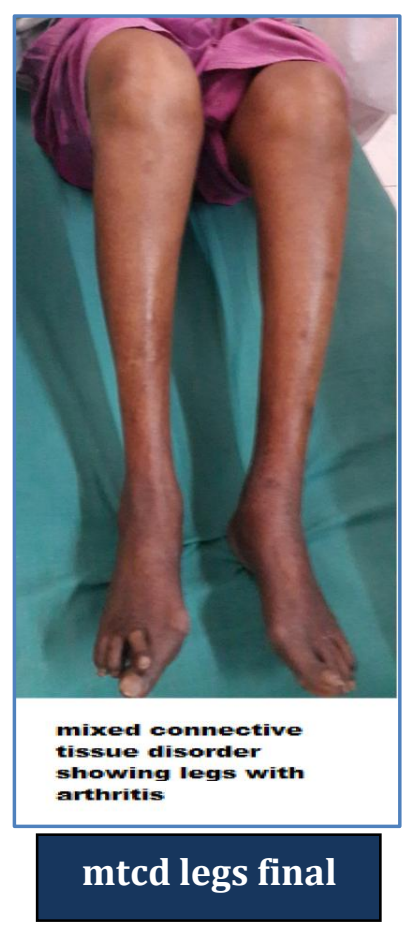

\section{AUTHORS:}

1. Narmadha Narendhran

2. Jamila Hameed

3. Abhinaya

4. Vivek Salguna

\section{PARTICULARS OF CONTRIBUTORS:}

1. Tutor, Department of Obstetrics and Gynaecology, Vinayaka Mission's Medical College \& Hospitals, Karaikal.

2. Professor, Department of Obstetrics and Gynaecology, Vinayaka Mission's Medical College \& Hospitals, Karaikal.

3. Post Graduate, Department of Obstetrics and Gynaecology, Vinayaka Mission's Medical College \& Hospitals, Karaikal.
4. CRRI, Department of Obstetrics and Gynaecology, Vinayaka Mission's Medical College \& Hospitals, Karaikal.

\section{NAME ADDRESS EMAIL ID OF THE CORRESPONDING AUTHOR:}

Dr. Narmadha Narendran,

Department of Obstetrics and Gynecology, Vinayaka Mission's Medical and Hospitals, Karaikal, Pondicherry - 609609, U. T. E-mail: jamilahameed@gmail.com

Date of Submission: 24/03/2014. Date of Peer Review: 25/03/2014. Date of Acceptance: 08/04/2014. Date of Publishing: 01/05/2014. 